(C) Elsevier Scientific Publishing Company, Amsterdam - Printed in The Netherlands

Research Papers

\title{
LONG- AND SHORT-TERM EARTHQUAKE PREDICTION IN KAMCHATKA *
}

\author{
S.A. FEDOTOV, G.A. SOBOLEV, S.A. BOLDYREV, A.A. GUSEV ${ }^{1}$,
}

A.M. KONDRATENKO, O.V. POTAPOVA, L.B. SLAVINA, V.D. THEOPHYLAKTOV, A.A. KHRAMOV and V.A. SHIROKOV

Institule of Volcanology, Petropavlousk-Kamchatsky (U.S.S.R.)

(Submitted October 13, 1975; revised version accepted July 1, 1976)

\section{ABSTRACT}

Fedotov, S.A., Sobolev, G.A., Boldyrev, S.A., Gusev, A.A., Kondratenko, A.M., Potapova, O.V., Slavina, L.B., Theophylaktov, V.D. Khramov, A.A. and Shirokov, V.A., 1976.

Long- and short-term earthquake prediction in Kamchatka. Tectonophysics, 37:

$305-321$.

This paper presents the results of long-and short-term earthquake prediction obtained during 1971-1974. They can be summarized as follows:

The map of long-term prediction for the Kurile-Kamchatka zone compiled in 1965 and supplemented in 1972 by S.A. Fedotov is in good agreement (in four of four possible cases) with recorded seismicity.

The results obtained allow us to suppose that the areas for which the $\log \left(E_{\mathrm{p}} / E_{\mathrm{s}}\right)$ of small earthquakes is low may be the areas of future large earthquakes .

Prediction of active periods for the Kamchatka earthquakes with $M \geqslant 7$ has been made on the basis of studying the correlation of seismicity with the lunar tide with a 18.6-year period. A possibility has been found for using the phenomenon of "induced forcshocks" for earthquake prediction, i.e., when a large remote earthquake induces small preceding events in the zone of preparation of a large earthquake.

The following three methods were used for operative short-term prediction of the time and place of future earthquakes with $M \geq 5.5$.

(1) Use of specific electrotelluric field anomalies, from 5 to 20 days in duration, which are recorded by a specially designed network of stations.

(2) Method of $V_{\mathrm{p}} / V_{\mathrm{s}}$ anomalies. The anomalously high and low $V_{\mathrm{p}} / V_{\mathrm{s}}$ values for a seismic station point to the possibility of large earthquakes near the latter.

(3) The earthquake statistics method described by Fedotov et al. in 1972.

Short-term seismic prediction is being made twice a week in two versions: Forecast 1 (for the whole of Kamchatka) and Forecast II (for each of six overlapping segments of the Kamchatka seismic zone).

This paper discusses the results of successful testing of short-term earthquake prediction during two years. During the "alarm" periods the probability of large earthquakes is double the average.

\footnotetext{
* Paper presented at the Symposium on Earthquake Forerunners Searching, Tash kent,
} May 26 June 1, 1974. 


\section{INTRODUCTION}

The first investigations on earthquake prediction in Kamchatka were undertaken in 1964 (Fedotov, 1965). The data obtained by 1971 were published in papers by Fedotov et al. (1972) and Myachkin et al. (1972).

The important step in studies of earthquake prediction was the beginning of tentative operative short-term prediction of the Kamchatka earthquakes with $M \geqslant 5.5$, based on data of long-term prediction as well as on a number of forerunners revealed from seismic and electrotelluric field data.

\section{INVESTIGATIONS ON LONG-TERM SEISMIC PREDICTION}

Considerable progress has been made during the past few years toward long-term seismic prediction.

In 1965, a map was compiled of probable areas in the regions of Kamchatka, Kurile Islands and northeastern Japan in which earthquakes with $M \geqslant 73 / 4$ are most likely to occur (Fedotov, 1965; 1968). In 1972, Fedotov et al. published the up-dated version of the map for 1971 and the following years. Later on, an analogous procedure of compilation of these maps has been used for the entire Pacific seismic belt (Sykes, 1972; Kelleher et al., 1974).

In accordance with the map published in 1972, between January 1971 and February 1974 two earthquakes with $M=73 / 4$ occurred; the first - in the Kamchatsky Bay near the northern extremity of the Kurile-Kamchatka seismic zone (Dec. 15, 1971) and the second - in the region of northeastern Hokkaido-the Lesser Kurile Islands (June 17, 1973). Both earthquakes occurred at the two of three places assumed to be the most probable locations of future earthquakes. In 1965, the prediction of the location of the future Kurile-Kamchatka earthquakes with $M \geqslant 73 / 4$ was initially assumed to be correct on the average in four out of five cases. In fact, between 1965 and February 1974, it proved to be correct in four out of four possible cases.

New data on the prediction of the location of large earthquakes have been obtained from studies of the value $\theta=\log \left(E_{\mathrm{s}} / E_{\mathrm{p}}\right)=K_{\mathrm{s}}-K_{\mathrm{p}}$, where $E_{\mathrm{s}}$ and $E_{\mathrm{p}}$ are the radiated energy of short-period S- and P-waves, and $K_{\mathrm{s}}$ and $K_{\mathrm{p}}$ are the corresponding energy classes. The technique of $\theta$ determination was described by Fedotov (1972). A map of the Kamchatka earthquake epicenters for 1968 to 1970 with $\theta$ differing from its average value by more than one and more than two standard deviations is shown in Fig. 1 . Since $\theta$-values proved to depend on $K_{\mathrm{s}}$ and on depth $h, \theta$-values corrected accordingly and designated $\Delta \theta_{10}$, were used.

The low $\theta$-values are concentrated in the regions southeast of Kamchatsky Cape and in the south of Kamchatka. Earthquakes with $M \geqslant 73 / 4$ and $M \geqslant$ $71 / 4$ occurred in these very regions on Dec. 15, 1971 and on Feb. 28, 1973, respectively. If the $\theta$ parameter is actually prognostic, the potential locations of future large earthquakes may be the regions of Kronotsky Cape and of the 


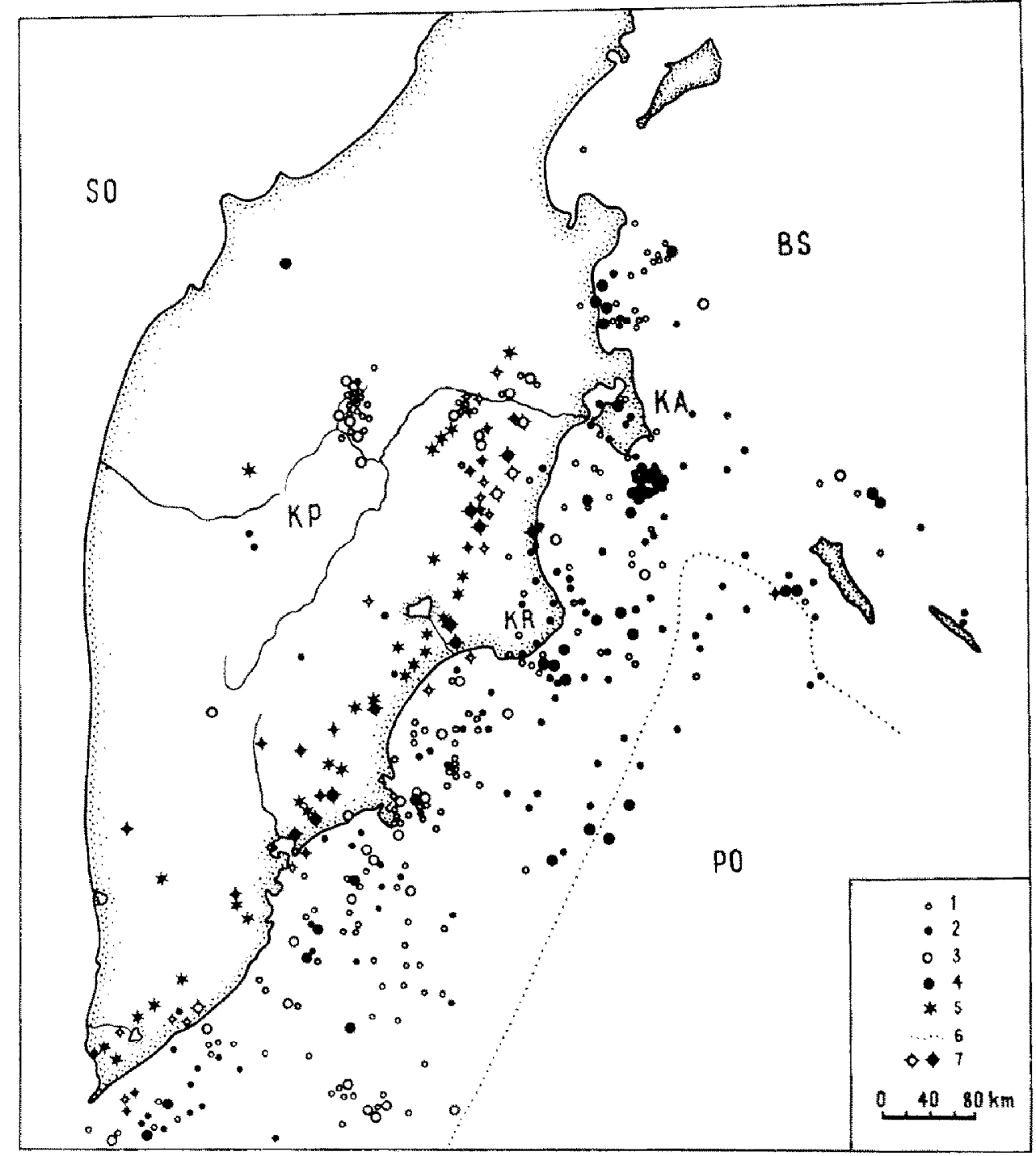

Fig. 1. Map of the Kamchatka epicenters of earthquakes for which $\left|\Delta \theta_{10}\right|>$ o for $1968-1970(\alpha=0.4$ in decimal logarithmic units $) . K P=$ Kamchatka Peninsula, $\mathrm{KA}=$ Kamchatsky Cape, KR = Kronotsky Cape, BS = Bering Sea, SO $=$ Sea of Okhotsk, $\mathrm{PO}=$ Pacific Ocean, $1,2,3,4=$ epicenters of earthquakes with $\sigma<\Delta \theta_{10}<2 \sigma,-2 \sigma<\Delta \theta_{10}<$ $-\sigma, \Delta 0_{10}>20, \Delta \theta 10<-20$, respectively; $5=$ active volcanoes; $6=$ the trench axis; $7=$ epicenters of earthquakes with a focal depth of more than $100 \mathrm{~km}$.

trench southeast of Kronotsky Bay. This forecast is also in good agreement with long-term seismic prediction (Fedotov, 1968).

The other approach to earthquake prediction was used by V.A. Shirokov who made an attempt to forecast the "active" and "quiet" time intervals on 
the basis of correlation between earthquakes and the 18.6-year component of the lunar tide related to rotation of the nodal line of the moon's orbit. The prognostic significance of this correlation was shown by Lamakin (1966); The connection between earthquakes and the 18.6-year tide was investigated for two large regions of the north western Pacific tectonic zone: (1) the Aleutian Islands; and (II) Kamchatka, Kurile Islands and northeastern Japan (35-58 N). Earthquakes with $M \geqslant 7$ and a focal depth of $0-70 \mathrm{~km}$ occurring during 1904-1972 (46 events) were investigated in region I. Earthquakes with $M \geqslant 73 / 4$ and a focal depth of 0-100 km occurring during 1896-1972 ( 48 events) were considered in region II. Earthquakes of the Kurile-Kamchatka zone occurring during a period of non-instrumental observations (1737-1895) with seismic intensity not less than 8 (6 events), were also included in the list of earthquakes for region II.

The distribution of earthquakes within the 18.6-year period is shown for both regions in Fig. 2. The beginning of the period was taken to be the epoch of maximum lunar inclination. Within the period one can distinguish an active phase enveloping for region I ( 44 of 46 events) and for region II (52 of 54 events). Its duration is of about two thirds of a period. The beginning of the phase in region I in comparison to region II occurs with a six-year delay. Statistical tests were carried out in two ways. The first test determined a binomial probability of occurrence of 44 out of 46 and of 52 out of 54 events during the 0.67 cycle. It was $0.5 \cdot 10^{-5}$ and $0.5 \cdot 10^{-6}$, respectively. In order to avoid the misleading influence of event clustering, numbers of event groups were used instead of event numbers in the second test. The event group was

a

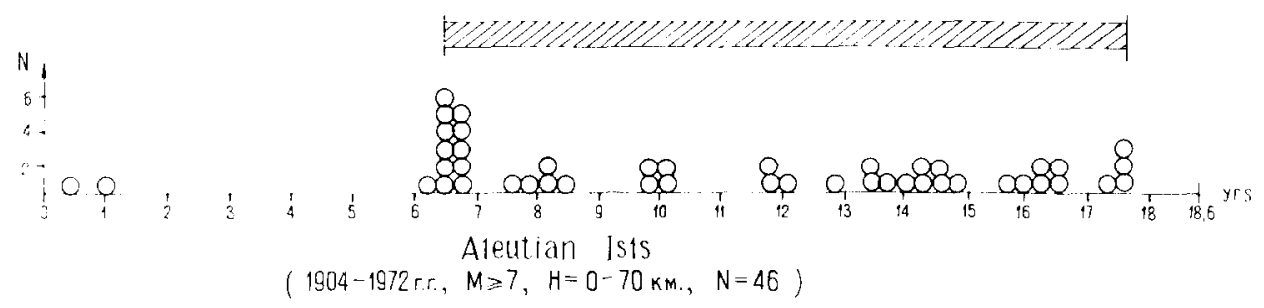

b

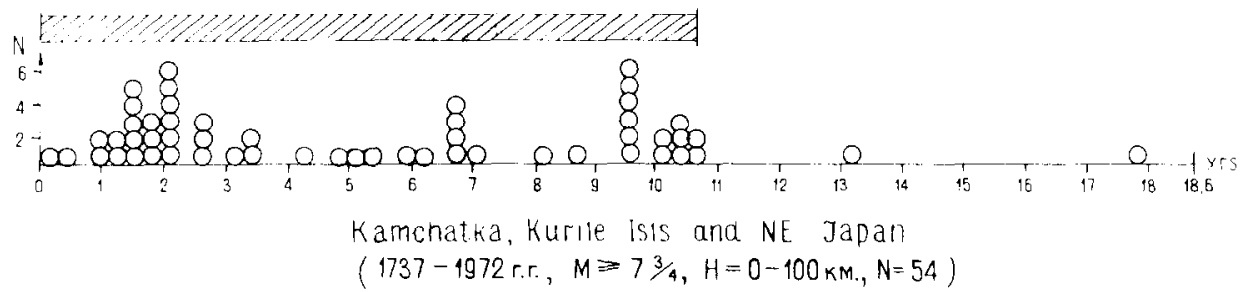

Fig. 2. The distribution of large earthquakes for two seismic regions within an 18.6-year period. Active phases of the cycle are shown by bars. 
taken to be a cluster of events not exceeding twelve months in duration or an individual event. Thus, we have obtained that 20 out of 22 and 15 out of 17 groups occurred during the active periods. New binomial probabilities are 0.01 and 0.05 , respectively. These low values point to variations of event frequency within a cycle. The correlation revealed can be used for earthquake prediction. In region I, the active phase should come between Sept. 1975 and July 1987. In region II, the current active phase should come to an end by February 1981. A phase of seismic quiescence is expected from 1981 to 1988. The occurrence probability of one or more earthquakes with $M \geqslant 73 / 4$ in region II during $1974-1980$ is estimated to exceed 0.95 in comparison to the period from 1981 to 1988 when it is less than 0.2 .

\section{$a$}
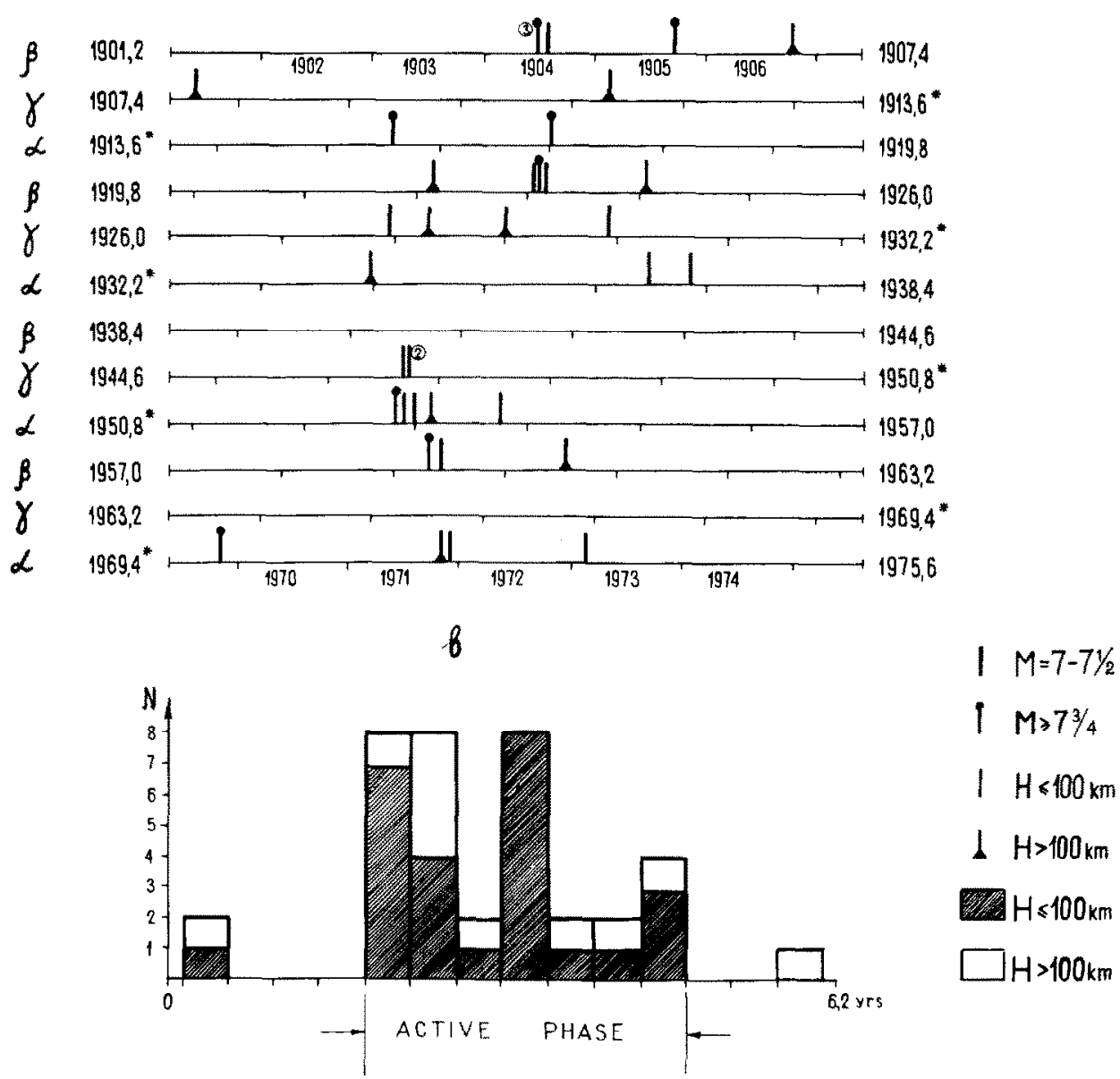

Fig. 3. The distribution of Kamchatka earthquakes with $M \geqslant 7$ for $1897-1973$ within 6.2-year periods (a), the corresponding histogram (b), $N$ is the number of events. 
The correlation revealed is also essential in terms of geodynamics. This correlation shows the marked influence of lunar tide forces on tectonic movements. The influence is different in adjacent seismic zones.

The time distribution of Kamchatka earthquakes with $M>7$ occurring between $49^{\circ}$ and $58^{\circ} \mathrm{N}$ from 1897 to 1973 was studied separately. Beginning from 1911, 37 earthquakes with $M>7,10$ of them with $M>73 / 4$, occurred in the region of Kamchatka. Eleven earthquakes occurred at a depth of more than $100 \mathrm{~km}$, two of them occurred deeper than $300 \mathrm{~km}$ (340 and $590 \mathrm{~km}$ ). Fig. 3 a shows the distribution of these earthquakes within successive 6.2-year intervals. The 6.2-year period is assumed to be an "overtone" of the main 18.6-year period. Each 18.6-year period includes three intervals designated as $\alpha, \beta$ and $\gamma$. Thus, the beginning of the $\alpha$-interval is the epoch of maximum lunar inclination. The boundaries of the intervals are shown in Fig. $3 \mathrm{a}$ with an accuracy of 0.1 year. The beginning of the $\alpha$-intervals is marked with asterisks.

Figure $3 \mathrm{~b}$ shows the 5-month interval distribution of Kamchatka earthquakes within a 6.2-year period. The histogram has revealed a 3.1-year phase of seismic activity during which 34 of 37 earthquakes and 15 of 17 event groups occurred. The binomial probabilities computed according to the above-described scheme are $1 \cdot 10^{-7}$ and $2 \cdot 10^{-3}$, respectively. Thus, the active phase can be distinguished rather definitely and this is supported by the fact that from 1737 to 1896 the nine largest earthquakes occurred during active phases of the 6.2-year cycles. Table I, showing the prediction of Kamchatka earthquakes for the period from 1974 to 2000 , was compiled in 1972. In corroboration of this prediction, two events occurred in 1973, one with $M=7.3$ near Kamchatka (Feb. 28, 1973) and another with $M=73 / 4$ in region II (June 17, 1973), and no events with $M>7$ occurred in region $I$.

One more investigation has been dealt with a certain relationship between earthquakes, first revealed by A.G. Prozorov (Prozorov and Rantsman, 1972) who analyzed earthquake data from the Catalogue of Middle Asia. This rela-

\section{TABLE I}

Forecast of periods of high and low probability for earthquakes in Kamchatka $\left(49-58^{\circ} \mathrm{N}\right)$ with $M \geqslant 7$ and $H=0-600 \mathrm{~km}$ for $1974-2000$ (by V.A. Shirokov).

Active phases

March 1977-March 1980

June 1983-June 1986

Sept. 1989-Sept. 1992

Nov. 1995-Nov. 1998
Quiet phases

Feb. 1974-Feb. 1977

Apr. 1980-May 1983

July 1986-Aug. 1989

Oct. 1992 - Oct. 1995

Dec. 1998-Jan. 2002

$P_{1}(N \geqslant 1)=0.83 \quad P_{2}(N \geqslant 1)=0.09$

$P_{1}(N \geqslant 1)$ and $P_{2}(N \geqslant 1)$ are the probabilities of earthquake occurrence in active and quiet phases, respectively. 
tionship was also noted by S.A. Fedotov and it was studied by A.A. Gusev who analyzed earthquake data from the Kamchatka and world catalogues. The phenomenon in question is that a large earthquake, let it be the A-event, induces soon after itself small earthquakes, the so-called "induced foreshocks", (B-events) in the area of preparation of a future large earthquake (C-event). Strictly speaking, to choose energy levels for A-, C- and B-events, the space-time density of B-events will exceed the mean density of events with the same energy if the time from $\mathrm{A}$ to $\mathrm{B}, t_{\mathrm{AB}}<T$, the time from $\mathrm{A}$ to $\mathrm{C} t_{\mathrm{AC}}<T^{\prime}$ and the distance from $\mathrm{B}$ to $\mathrm{C} d_{\mathrm{BC}}<D$, when $T, T^{\prime}$ and $D$ are certain threshold values.

For example, if $M_{\mathrm{s}}(\mathrm{A}, \mathrm{C})>7.75, m_{\mathrm{b}}(\mathrm{B}) \geqslant 4.0, T=1.0$ day, $T^{\prime}=1$ year and $D=300 \mathrm{~km}$, the density of B-events will exceed by approximately one order the mean density of events with $m_{\mathrm{b}} \geqslant 4.0$ in the same region and during the same period. Table II * presents the main parameters of the phenomenon that were determined from data of three catalogues.

Summarizing these data, the following main regularities may be inferred: time $t_{\mathrm{AB}}$ is from 0.1 to 10 days, time $t_{\mathrm{AC}}$ is from 0.1 to 1 year, the energy

\section{TABLE II}

The main parameters of the phenomenon of "induced foreshocks" for three earthquake catalogues

\begin{tabular}{llll}
\hline & $\begin{array}{l}\text { World } \\
(1960-1971)\end{array}$ & $\begin{array}{l}\text { Kamchatka } \\
(1964-1968)\end{array}$ & $\begin{array}{l}\text { Middle Asia } \\
\text { (after Prozorov) }\end{array}$ \\
\hline $\begin{array}{l}\text { Magnitude } \\
\text { (Energy class) A, C }\end{array}$ & $M_{\mathrm{s}} \sim 7.5-8$ & $\begin{array}{l}K \geqslant 13 \\
(\sim M \geqslant 5.5)\end{array}$ & $\begin{array}{l}K \geqslant 14 \\
(\sim M \geqslant 5.6)\end{array}$ \\
$\begin{array}{l}\text { Magnitude } \\
\text { (Energy class) B }\end{array}$ & $m_{\mathrm{b}} \geqslant 4.2$ & $\begin{array}{l}K \geqslant 8 \\
(\sim M \geqslant 2.2)\end{array}$ & $\begin{array}{l}K \geqslant 9 \\
(\sim M \geqslant 2.3)\end{array}$ \\
$t_{\mathrm{AB}}$ & $0.1-10$ day & $0.1-5$ day & - \\
$t_{\mathrm{AC}}$ & $0.2-1$ year & $0.1-0.5$ year & up to a year \\
$d_{\mathrm{BC}}$ & $100-500 \mathrm{~km}$ & $20-40 \mathrm{~km}$ & $100 \mathrm{~km}$ \\
$d_{\mathrm{AC}}$ & all over the world & up to $700 \mathrm{~km}$ & up to $1000 \mathrm{~km}$ \\
\hline
\end{tabular}

${ }^{\star} K$-values used in column 2 and throughout the paper are energy classes $K_{\mathrm{S1.2}}^{\mathrm{F} 68}$ for Kamchatka earthquakes introduced by S.A. Fedotov (1972). Their correspondence with magnitude scales is shown below.

\begin{tabular}{llllll}
\hline$K$ & 12 & 13 & 14 & 15 & 16 \\
\hline$m_{\mathrm{b}}$ & 5.0 & 5.5 & 6.0 & 6.5 & 7.0 \\
$M_{\mathrm{s}}$ & 4.9 & 5.6 & 6.3 & 6.9 & 7.5 \\
\hline
\end{tabular}

$K$-values in column 3 correspond to the Rautians's scale $K^{\mathrm{R} 61}$. Their correspondence to the $K^{\mathrm{F} 68}$ scale is seen from the following formula: $K^{\mathrm{R} 61} \approx K^{\mathrm{F} 68}+0.6$. 
difference between $A$ and $C$ on the one hand, and $B$ on the other, is $4-6$ decimal orders and $d_{\mathrm{BC}}$ is close to the size of the C-event epicentral area or is somewhat greater.

The phenomenon considered can be used for predicting the time of a large earthquake $(M \sim 8)$ in a certain segment of a seismic zone. There had been chosen three areas in which the following earthquakes took place: Dec. 31 , 1966, $M=8.0$, Santa Cruz Isles; May 16, 1968, $M=8.2$, Hokkaido Island; Dec. 15, 1971, $M=7.7$, Kamchatka. All earthquakes over the world with $M$ $\geqslant 7.5$ as A-events were taken. In addition, events with $M \geqslant 7.3$ in the Pacific belt north of the equator were included in the A list for the Dec. 15, 1971 Kamchatka earthquake. As small-event lists (S-lists) the following sources were used: for the first C-event, the list from "BISC Regional Catalogue" for geographical regions Nos. 183 and 184 with $m_{b} \geqslant 4.0$; for the second Cevent, the same source for regions Nos. 223 and 224, and for the third event the list of Kamchatka earthquakes (local net data) for the region $54-58^{\circ} \mathrm{N}$, $158-168^{\circ} \mathrm{E}$, with $K \geqslant 11.0\left(\sim m_{\mathrm{b}} \geqslant 4.5\right)$. Thus, instead of the condition $d_{\mathrm{BC}}<D, d_{\mathrm{BC}}$ values were restricted by the fact that both $\mathrm{B}$ - and C-events occurred within the same segment of the seismic zone. As a probable B-event there was taken an event from the corresponding S-list following the A-event. If the "foreshock" B-events did not occur, times $t_{\mathrm{AB}}$ should be close to the recurrence lime $T_{\mathrm{r}}$ for the corresponding $\mathrm{S}$-list. Then, the $t_{\mathrm{AB}}$ distribution would be exponential: $P\left(t_{\mathrm{AB}}\right)=\exp \left(-t_{\mathrm{AB}} / T_{\mathrm{r}}\right) / T_{\mathrm{r}}$. The upper and lower $10 \%$ for this distribution are $0.1 T_{\mathrm{r}}$ and $2.3 T_{\mathrm{r}}$; the observed $t_{\mathrm{AB}}$ values would mainly be within these limits.

Figure 4 shows the times $t_{\mathrm{AB}}$ plotted in logarithmic scale versus time $t_{\mathrm{AC}}$ to the future large earthquake. $T_{\mathrm{r}}$ values for all the three $\mathrm{S}$-lists happened to coincide; they are close to 12 days. $T_{\mathrm{r}}, 0.1 T_{\mathrm{r}}$ and $2.3 T_{\mathrm{r}}$ levels were also

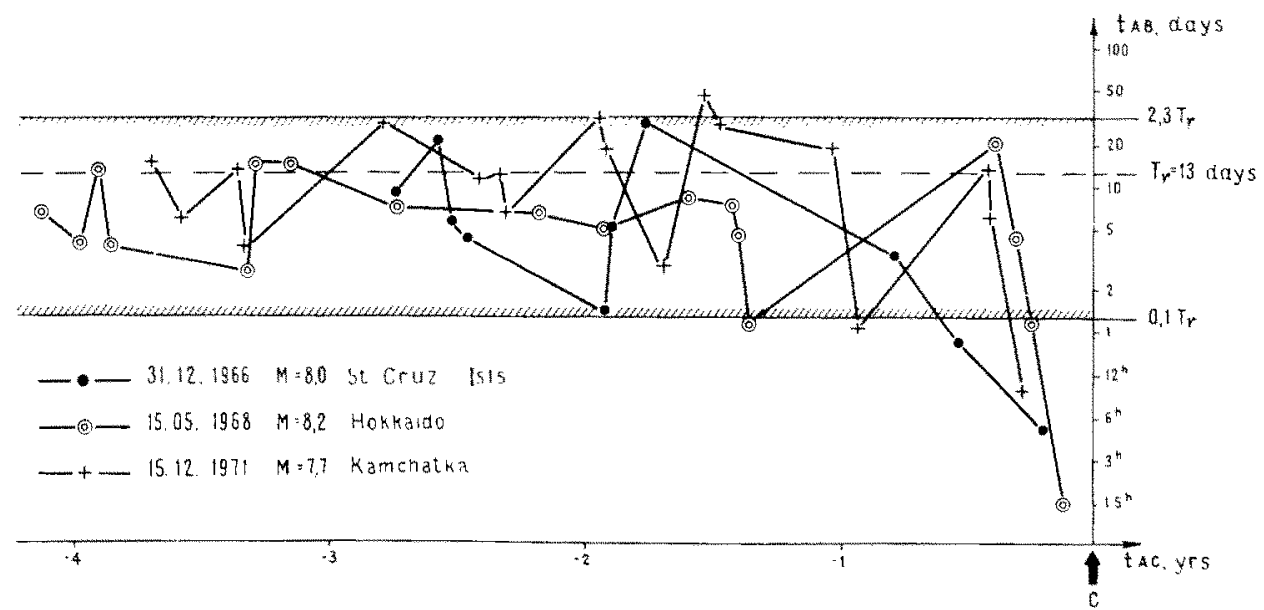

Fig. 4. Variations of $t_{\mathrm{AB}}$ before three large earthquakes. $0.1 T_{\mathrm{r}}$ and $2.3 T_{\mathrm{r}}$ levels correspond to the upper and lower $10 \%$ limits for the Poisson process. 
plotted in Fig. 4. One can see that during the period from 4 to 1 year prior to $\mathrm{C}$-events, $t_{\mathrm{AB}}$ values in all three cases are almost entirely with in the $10 \%$ limits, but during a year before a large earthquake, values lower than $0.1 T_{\mathrm{r}}$ are observed and the last of the $t_{\mathrm{AB}}$ values observed 1-3 months prior to $\mathrm{C}$ events is less than $0.03 T_{\mathrm{r}}$ in all the three cases. One may infer that the phenomenon of "induced foreshocks" is rather pronounced in order to be used for real-time earthquake prediction.

TENTATIVE SHORT-TERM PREDICTION OF SHALLOW KAMCHATKA EARTHQUAKES WITH $M \geqslant 5.5$

Investigations on earthquake prediction in Kamchatka have revealed a number of forerunners occurring 5-20 days before an earthquake. They were used as a basis for the Program for tentative short-term prediction of shallow Kamchatka earthquakes with $K_{\mathrm{S} 1.2}^{\mathrm{F} 68} \geqslant 13$ (or $\sim M \geqslant 5.5$ ) compiled in December 1971 by S.A. Fedotov and G.A. Sobolev. Tentative prediction has continuously been carried out according to this program since January 1 , 1972. The forerunners, technique and results of prediction obtained during the period from Jan. 1, 1972 to Apr. 15, 1974 are discussed briefly below.

Registration of the electrotelluric field (ETF), aimed at the search for forerunners of large earthquakes, has been conducted on the eastern shore of Kamchatka since 1966 . Observations were carried out by a network of stations installed at distances of $80-200 \mathrm{~km}$ from each other (Fig. 5). Lead electrodes were used as sensors placed at a depth of $2 \mathrm{~m}$, in pairs oriented in $\mathrm{N}-\mathrm{S}$ and $\mathrm{E}-\mathrm{W}$ directions. To improve reliability, from four to ten independent pairs were used at each station. The automatically controlled recording system entailed the recording of potential differences every hour. All these investigations allowed us to establish specific features of anomalies of the electrotelluric field before an earthquake with $K \geqslant 13$ (Sobolev et al., 1972, 1974; Sobolev, 1973). The duration of anomalies varied from 5 to 15 days and their amplitudes amounted to $50 \mathrm{mV} / 200 \mathrm{~m}$. The slope on the rise of the anomaly was greater than on its return to the initial level. The anomaly detection was complicated by noise caused by precipitation, snow melting, magnetic storms and occan tides.

The recorded readings of potential differences of each pair of electrodes were averaged for each 24 hours and then were plotted on the time diagrams. The latter were used as the initial data for ETF operative prediction. The anomalous variations were suggested to be predictive only when they coincided in time ( \pm 1 day) and were close in form at least at the parallel pairs of a station. To predict the time of the future earthquake, data of Shipunsky station were used, since it is located in the center of the Kamchatka seismic region. To estimate a possible location of the future earthquake, data of other stations were used. The results are illustrated in Table III and Fig. 6.

The detection of predictive ETF anomalies were also carried out by a special computer program by V.N. Bogaevsky and G.A. Sobolev using the same 


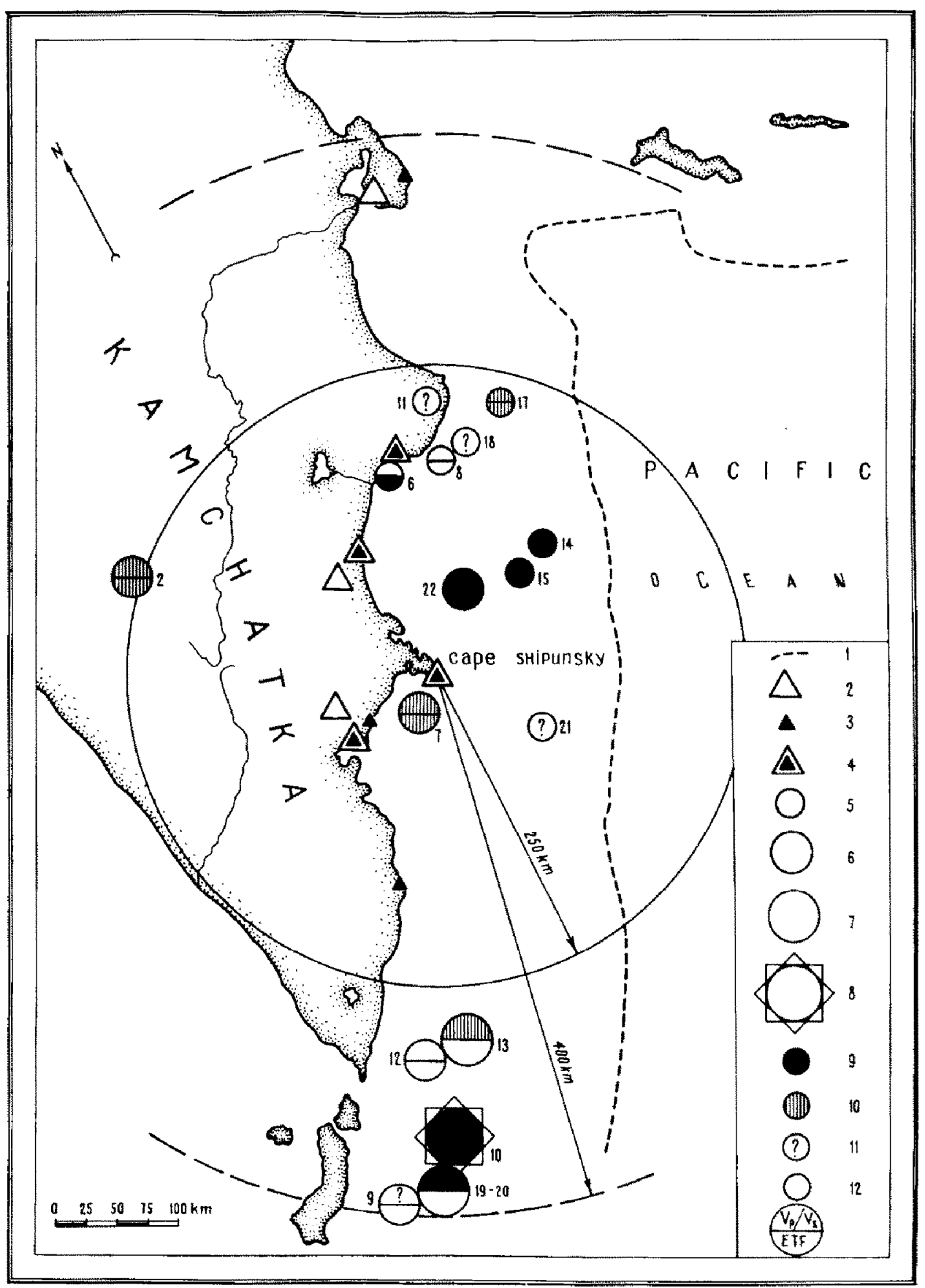




\section{TABLE III}

The results of tentative short-term prediction of the Kamchatka earthquakes with $K \geqslant 13$ $(\sim M \geqslant 5.5)$.

\begin{tabular}{llrlll}
\hline Method & $N$ & $N_{\mathrm{p}}$ & $L$ & $P_{\mathrm{p}}$ & $I$ \\
\hline ETF I & 14 & 9 & 0.42 & 0.64 & 1.54 \\
EQS & 14 & 5 & 0.45 & 0.36 & 0.80 \\
Forecast I & 13 & 3 & 0.14 & 0.23 & 1.65 \\
ETF II & 12 & 8 & 0.29 & 0.67 & 2.30 \\
$V_{\mathrm{p}} / V_{\mathrm{S}}$ & 14 & 10 & 0.56 & 0.71 & 1.28 \\
Forecast II & 12 & 7 & 0.22 & 0.58 & 2.64 \\
\hline
\end{tabular}

initial data. The first stage of algorithm consisted of smoothing the high-frequency noise, of the construction of a seasonal trend line and of subtraction of this trend from the smoothed curve. Then all the curves corresponding to parallel pairs of a station were averaged in order to increase the signal-to-noise ratio. The curve obtained was smoothed again with a weight function specially constructed to detect 5-20-day anomalies of the above described form. The output of the program was function $(\overline{\Delta V})^{2}$ which is close in the physical sense to the square of the intensity of the electrotelluric field.

Increasing values of $(\overline{\Delta V})^{2}$ correspond to the beginning of the alarm period. Figures 5 and 7 illustrate that high values of $(\overrightarrow{\Delta V})^{2}$ were observed prior to earthquakes at a distance of up to $250 \mathrm{~km}$ from Shipunsky station. In addition, a sharp rise was noted in the $(\overline{\Delta V})^{2}$ plot before earthquake No. 10 with $M=7.3$ which occurred on Feb. 28, 1973 in the south of Kamchatka.

Investigation on space-time variations of the $\kappa$-ratio of P- and S-wave velocities have been carried out in Kamchatka since 1972. Single $k$-values were estimated from data of one station (usually the closest to the focus) according to the formula:

$\kappa=\frac{t_{\mathrm{s}}-t_{\mathrm{p}}}{t_{\mathrm{p}}-\frac{t_{0}}{t_{0}}+1}$

Fig. 5. Map showing the epicenters of Kamchatka earthquakes for which correlation of $\left(\Delta \bar{V}_{\mathrm{p}} / V_{\mathrm{s}}\right)^{2}$ and of $(\overline{\Delta v})^{2}$ anomalies with the future earthquake was considered: $1=$ the trench axis; $2=$ seismic station; $3=$ ETF station; $4=$ joint seismic and ETF station. Epicenters of earthquakes with energy class: $5-K=13 ; 6-K=14 ; 7-K=15 ; 8-K=16$. Correlation of an earthquake with forerunners: 9 - earthquake was preceded by marked anomaly at Shipunsky station; 10 - less distinct anomaly; 11 - a relation of maximum to a given earthquake is questionable; 12 - no preceding anomalies. The symbols of situations $(9-12)$ are given: for method $V_{\mathrm{p}} / V_{\mathrm{s}}$ in the upper semicircles of all the epicenter circles; for method ETF in the lower semicircles. If a circle is not divided, the situation is the same according tot the both methods. 


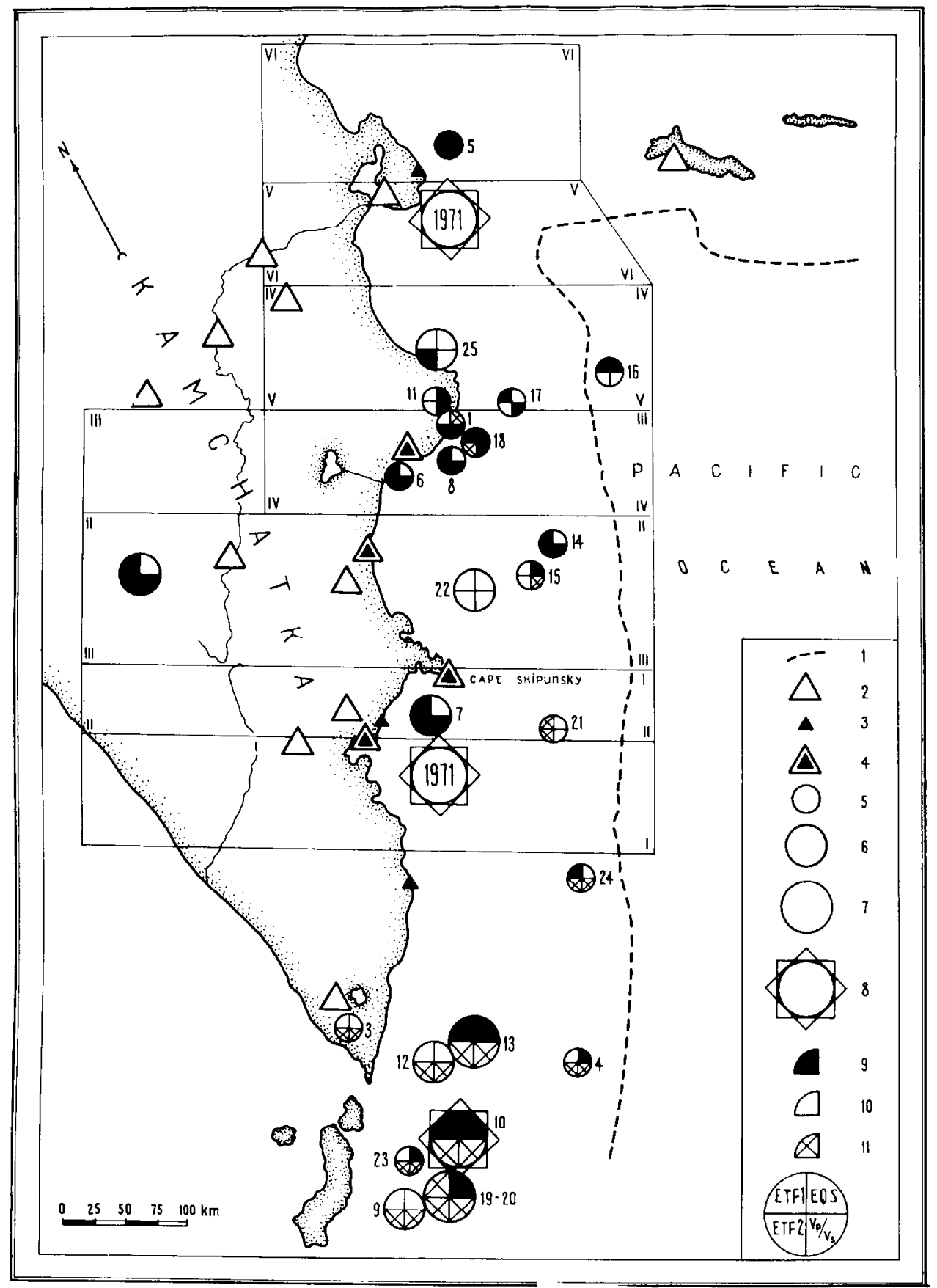

Fig. 6. Map showing the epicenters of Kamchatka earthquakes with $K \geqslant 13$ for which operative prediction was made. Symbols $1-8$ as in Fig. 5. The results of forecast: 9 alarm was given before the earthquake; 10 - no alarm was given (miss); 11 - technical gap in data. Symbols $9-11$ in four sectors of the epicenter circle demonstrate the results of four methods used in prediction of the earthquake, according to the scheme in the lower right corner. 


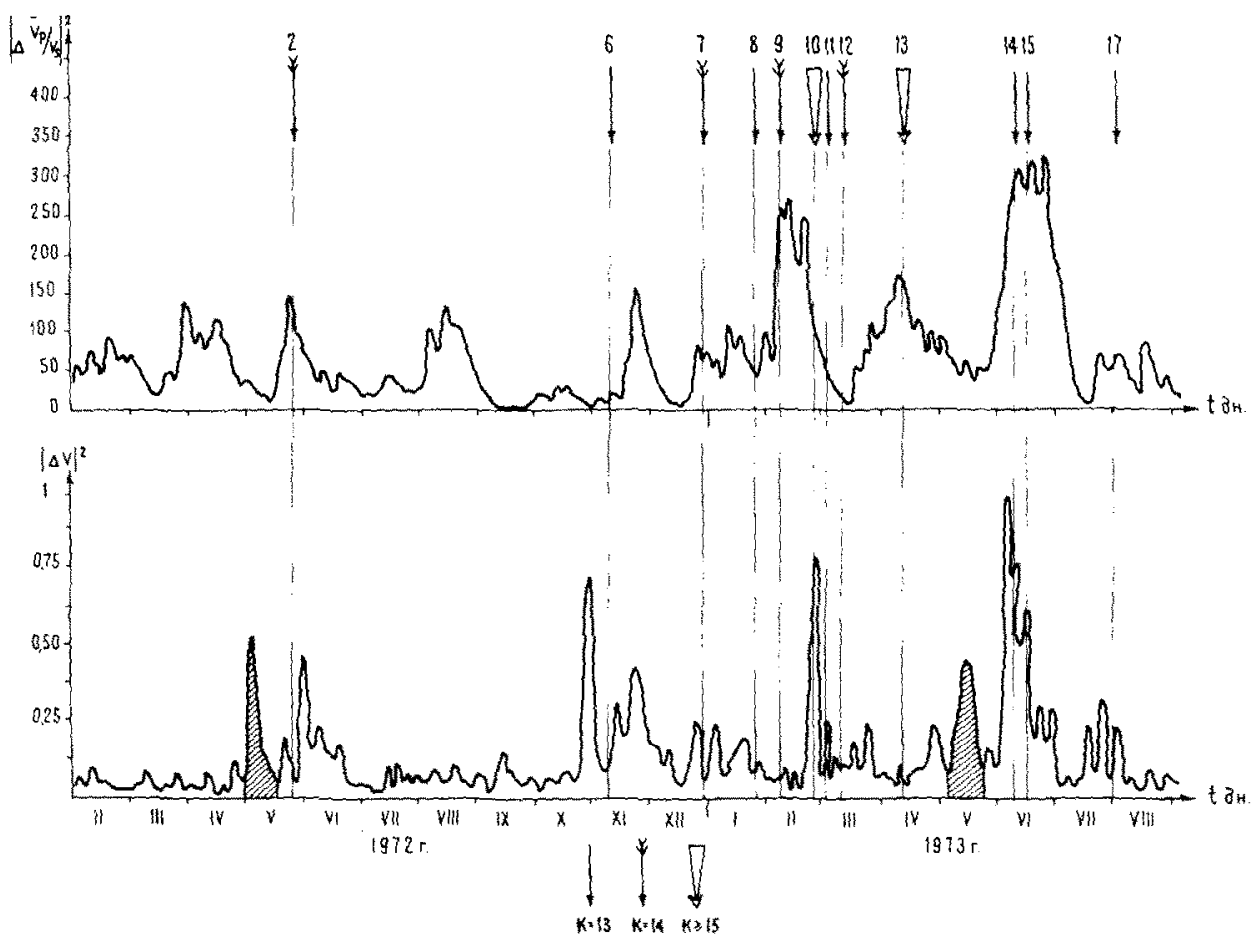

Fig. 7. Detection of forerunners of Kamchatka earthquakes according to special computer programs. Upper part: $V_{p} / V_{s}$ data; lower part: the ETF data. Hatches denote ETF reaction on snow melting. Both plots are for Shipunsky station.

where $t_{\mathrm{p}}$ and $t_{\mathrm{s}}$ are $\mathrm{P}$ and $\mathrm{S}$ arrival times for the station, and $t_{\mathrm{o}}$ is the origin time determined from data of the whole Kamchatka station net. The initial data for obtaining single values were taken from the Bulletin of this station net. For each station data on earthquakes without limitation of energy class and depth, in a radius of $160 \mathrm{~km}$ from a station, were used. Continuous observations were carried out for the six coastal stations of Kamchatka closest to the main focal zone (see Fig. 5). The data of not less than two stations were available for each chosen site of the focal zone. The standard error of a single $k$-value was estimated to be $0.045-0.036$ for $t_{s}-t_{p} \sim 8-10 \mathrm{sec}$ if one takes the standard errors of $t_{\mathrm{s}} t_{\mathrm{p}}$ and $t_{\mathrm{o}}$ as independent and equal to $0.3,0.3$ and $0.5 \mathrm{sec}$, respectively. These suggestions are roughly true when $t_{\mathrm{s}}-t_{\mathrm{p}} \approx 10$ sec and the number of stations is more than five. On the other hand, standard deviation $\sigma$ of the distribution of all single $k$-values, which were observed during two years, was 0.036 (the average value was 1.73 ). Hence, the signalto-noise ratio was rather low.

In order to find predictive anomalies, $\kappa$-time series were examined for the six stations during the period from Jan. 1, 1971 to Apr. 20, 1974. It has been found that large $\kappa$-deviations of up to $\pm 12 \%$ tend to precede earth- 
quakes with $K \geqslant 12$ near the same station. These deviations begin $10-20$ days before an earthquake and last for some time after it. Therefore, the emergence of anomalously high and low $\kappa$-values during the 2 -day period beyond $\pm \sigma$-interval was considered to be a forerunner of an earthquake with $k \geqslant 13$. "Alarm" was announced twenty days beforehand from the moment of emergence of anomalous values. The results of this technique of prediction are illustrated in Table III and Fig. 6.

The forecast based on $\kappa$-values was compiled for the period from Jan. 1 , 1971 to Sept. 1, 1973 retrospectively and from Sept. 1, 1973 to the present moment in operative mode, using a special computer program. The algorithm included the calculation of differences between the current and average $\kappa$ values, the use of weight coefficients in order to decrease the influence of gross errors, and of separate smoothing of $\kappa_{\min }$ and $\kappa_{\max }$ time series using a special weight function (Sobolev and Slavina, 1974). $\left(\kappa_{\min }\right.$ and $\kappa_{\max }$ are minimum and maximum $k$-values observed for each successive 2-day period). Then we obtained the following output function:

$\left(\Delta \overline{V_{\mathrm{p}} / V_{\mathrm{s}}}\right)^{2}=\sum_{i=1}^{n}\left(\Delta \kappa_{\min } \cdot P_{i}\right) \cdot \sum_{i=1}^{n}\left(\Delta \kappa_{\max } \cdot P_{i}\right)$

where $P_{i}$ is the weight, $n$ is the length of the smoothing interval. Figure 7 shows the $\left(\Delta \overline{V_{\mathrm{p}} / V_{\mathrm{s}}}\right)^{2}$ plot for Shipunsky station during the period from Feb. 1,1972 to Dec. 31,1973 . The earthquake moments are pointed out by arrows. The numbers of arrows correspond to the numbers of earthquakes in Fig. 5. A comparison of Fig. 7 with the map of epicenters in Fig. 5 shows that most earthquakes with $m_{\mathrm{b}} \geqslant 5.5$ occurring in a radius of up to $250 \mathrm{~km}$ from Shipunsky station were preceded by a considerable increase of the $\left(\Delta \bar{V}_{\mathrm{p}} / \bar{V}_{\mathrm{s}}\right)^{2}$ function. When more than one earthquake occurred within Kamchatka within small time intervals, the prognostic increase of $\left(\Delta \bar{V}_{\mathrm{p}} / \bar{V}_{\mathrm{s}}\right)^{2}$ before some of them cannot be definitely clarified. In a number of cases, considerable $\left(\Delta \bar{V}_{\mathrm{p}} / \bar{V}_{s}\right)^{2}$ maxima were noticed prior to large earthquakes with $K \geqslant 14$ in the south of Kamchatka. A comparison of the $\left(\Delta \bar{V}_{\mathrm{p}} / \bar{V}_{\mathrm{s}}\right)^{2}$ and of $(\overline{\Delta V})^{2}$ plots in Fig. 7 indicates that for the second method (ETF) the warning time is shorter.

The earthquake statistics (EQS) method of prediction has been elaborated using the catalogue of Kamchatka earthquakes for 1965-1970) (Fedotov et al., 1972; Gusev, 1974). It is based on the following values estimated in 5-day intervals: $\hat{\gamma}$ estimate of the parameter of the earthquake distribution ${ }^{*}$, maximum energy class $\bar{K}$ and a range of earthquake numbers $d$ in three successive 5 -day intervals. These three values for two successive 5-day intervals are used for prediction of a large earthquake which may occur during the next 5 -day in-

\footnotetext{
* $\gamma$ corresponds to $b$-value of magnitude distribution $\log N(M)=a+b M$. Approximately, $b-1.5 \gamma$.
} 
terval. Alarm is announced if the product of likelihood ratios for the six mentioned values exceeds the fixed level.

The tentative short-term prediction of Kamchatka earthquakes included prediction of the time of earthquakes with $K \geqslant 13$ for the entire region (Forecast I) and prediction of the time and place of earthquakes with $K \geqslant 13$ (Forecast II). For Forecast II, the region was arbitrary subdivided into overlapping segments (see Fig. 6).

Data for prediction were gathered from $13-15$ seismic stations and from five electrotelluric field recording stations.

Every day at 1700 hours local time, operators transmitted by radio P- and S-wave arrival times, energy class of earthquakes and average values of potentials of the electrotelluric field for the previous day. From these data, along with seismograms of the Petropavlovsk seismic station, the earthquake origin time, coordinates and energy were determined.

Data of the electrotelluric field and of the earthquake-statistics method were used in Forecast I. Forecast II was based on methods of the velocity ratio $V_{\mathrm{p}} / V_{\mathrm{s}}$ and of the electrotelluric field, using data obtained at the closest stations to the region under question. Alarm was announced in Forecast I or in Forecast II when it was given by both methods. Otherwise, a "quiet period" was announced in the corresponding forecast. The final decision, after discussion by a research group, was entered in the minutes. During the period from Jan. 1, 1972 to Apr. 20, 1974, 235 meetings of the research group, representing 235 estimates of seismic activity, have been held. Thus, prediction was carried out three or four days before hand. There were several gaps in compiling Forecast I or Forecast II because of technical reasons. The prediction procedure was the same on the whole, with the exception of some improvements concerning the rules for announcing "alarm" and for relaxing it; in addition, prediction by the $V_{\mathrm{p}} / V_{\mathrm{s}}$ method, at first compiled by hand, has been made by a computer since Sept. 1, 1973.

Table III and the map in Fig. 6 show the results of tentative short-term prediction of the Kamchatka earthquakes. Earthquakes with $K \geqslant 13$ are shown on the map for the region for which the forecasts were compiled (15 events). Earthquakes near the focal zone of the February 28, 1973 event with $M=7.3$ (No. 10) are also shown on the map since some parameters used proved to correlate with the pre-earthquake situation in this region. Earthquakes are numbered in chronological order. The black and white sectors in a circle in Fig. 6 point to the presence or absence of alarm prior to a given earthquake, using various methods of tentative short-term prediction. Technical gaps are noted by oblique crosses. In Table III the authors use the following values to characterize the methods used quantitatively:

$N$ is the number of earthquakes with $K \geqslant 13$ which could be predicted by the given method;

$N_{\mathrm{p}}$ is the number of earthquake predicted; I;

$L=\Sigma T_{\mathrm{a}} / T$ is the ratio of total alarm time $\Sigma T_{\mathrm{a}}$ to the total time of Forecast 
$L=\left(\Sigma T_{\mathrm{a}} \cdot D_{\mathrm{a}}\right) /(T \cdot D)$ is the ratio of the sum of products of alarm time intervals $T_{\mathrm{a}}$ and the length of the region of alarm along the focal zone $D_{\mathrm{a}}$, to the product of the total prediction time $T$ and the region length $D$ for Forecast II;

$P_{\mathrm{p}}=N_{\mathrm{p}} / N$ is the probability of detection;

$I=P_{\mathrm{p}} / L$ is the efficiency of prediction (the ratio of earthquake density within the alarm time to the average frequency).

Table III illustrates that, according to parameter $I$, the method of the electrotelluric field is of the most efficiency. Mention is to be made of increase of $I$ when all the methods are used in combination. The $I$-increase in Forecast $I$ is rather paradoxical since the result of one of the methods used (EQS) was at a level of "random prediction" $(I=0.8)$. This $I$-increase is accounted for by a sharp decrease of "false alarm" time. Thus, a combined use of various methods seems to be one of the hopeful ways of increasing efficiency of prediction. The results of the earthquake statistics method were rather good for 1970 and 1971 in contrast to those of 1972-1974 (see Table III) when current predictions were compiled on the basis of operative data transmitted by radio. Therefore, the initial catalogue was corrected using standard Bulletin data, and prediction was repeated retrospectively for 1972 and 1973. However, no improvement has been obtained. The possible reasons of this phenomenon are the non-stationary statistical properties of the seismic regime and a low precision of the estimates of likelihood ratio. In particular, the better results obtained for 1970 and 1971 were caused in part by more pronounced clustering of large earthquakes during this period in comparison to 1972 and 1973.

It has been found that the efficiency of prediction can be improved by substituting a constant time interval for the interval of variable length. Several versions of the algorithm improvement were tested, using only the $\hat{\gamma}$ predictor. In all cases, alarm is announced if the low $\hat{\gamma}$-values $(\hat{\gamma}=0.3-0.35)$ were observed in the previous time interval. Then the relative alarm time $L=$ $30 \%$, and the efficiency value $I=2-2.5$. This order of $I$-values seems to be maximum for the method given.

\section{CONCLUSION}

Long-term seismic prediction in Kamchatka entails the specification of the place of future earthquakes with $M \geqslant 73 / 4$, time of earthquakes with $M \geqslant 7$, expected maximum magnitude during 5-year intervals (50\% probability) and other parameters (Fedotov et al., 1972). There is a possibility of improving this prediction if one uses data on focal mechanisms and repeated geodetic measurements. Of use may also be the anomalous $\theta$-variations and interrelated earthquake sequences.

The tentative short-term seismic prediction carried out during two years has resulted in a possibility of predicting earthquakes with $K \geqslant 13,3-5$ days beforehand with a probability twice as large as the hypothetical result of 
"random prediction". The efficiency obtained by a complex of methods is very low for practical use, because of the long warning time amounting to several days, low location accuracy amounting to $10^{4} \mathrm{~km}^{2}$ and small reliability. It appears that prediction reliability cannot be improved without knowledge of the physical nature of previously revealed forerunners and without the use of the new forerunners (geodetic and seismologic). All this should permit of finding a region of eartquake preparation and to observe its state of tension in detail. In order to improve the precision of time prediction, its expedient to continue a search for more short-term forerunners, in the electromagnetic field in particular. In one succeeds in finding two or three more methods of short-term prediction of eartquakes with $K \geqslant 13(M \geqslant 51 / 2)$ with a probability $1.5-2$ times greater than that of "random prediction", then short-term prediction will be of use in practice.

\section{REFERENCES}

Fedotov, S.A., 1965. On regularities of distribution of large earthquakes of Kamchatka, Kurile Islands and northeastern Japan. Tr. Inst. Fiz. Zemli, Akad. Nauk SSSR, 36 (203): 66-93 (in Russian).

Fedotov, S.A., 1968. On seismic cycle, possibilities of quantitative seismic zoning and long-term seismic prediction. In: Seismicheskoe raionirovanie SSSR. Nauka, Moscow, pp. 121-150 (in Russian).

Fedotov, S.A., 1972. Energy classification of the Kurile-Kamchatka Earthquakes and the Problem of Magnitudes. Nauka, Moscow, $116 \mathrm{pp}$. (in Russian).

Fedotov, S.A., Gusev, A.A. and Boldyrev, S.A., 1972. Progress of earthquake prediction in Kamchatka. Tectonophysics, 14 (3/4): 279-286.

Gusev, A.A., 1974. Earthquake prediction based on earthquake statistics. In: Seismichnost', seismicheskiy prognoz, svoistva verkhnei mantii i ikh svyaz's vulkanizmom. Nauka, Novosibirsk, pp. 109-119 (in Russian).

Kelleher, J., Sykes, L. and Oliver, J., 1974 . Possible criteria for predicting earthquake locations and their application to major plate boundaries of the Pacific and the Caribbean. J. Geophys. Res., 78 (14): 2547-2585.

Lamakin, V.V., 1966. On periodicity of the Baikal earthquakes. Dokl. Akad. Nauk SSSR, 170 (2): $410-413$ (in Russian).

Myach kin, V.J., Sobolev, G.A., Dolbilkina, N.A., Morozov, V.N. and Preobrazhensky, V.B., 1972, The study of variations in geophysical fields near focal zones of Kamchatka. Tectonophysics, $14(3 / 4): 287-294$.

Prozorov, A.G, and Rantsman, E.Ya., 1972. Earthquake statistics and morphostructures of eastern Middle Asia. Dokl. Akad. Nauk SSSR, 207 (2): 341-344 (in Russian).

Sobolev, G.A., 1973. Possibilities of operative earthquake prediction according to electrotelluric observations. In: Predvestniki zemletryasenii. VINITI, Moscow (in Russian).

Sobolev, G.A. and Slavina, L.B., 1974. Rapid variations of electric and seismic properties of medium in a seismoactive region. Dokl. Akad. Nauk SSSR, 215 (5): 1101-1104 (in Russian).

Sobolev, G.A., Morozov, V.N. and Migunov, N.I., 1972. The electrotelluric field and a large earthquake in Kamchatka. Izv. Akad. Nauk SSSR, Fiz. Zemli, 1: 73-80 (in Russian).

Sykes, L.R., 1972. Aftershock zones of great earthquakes, seismicity gaps and earthquake prediction for Alaska and the Aleutians. J, Geophys. Res., 76 (32): 8021-8042. 